\author{
Marquette University \\ e-Publications@Marquette
}

$10-2018$

\title{
Metagenomics Reveal Triclosan-Induced Changes in the Antibiotic Resistome of Anaerobic Digesters
}

\author{
M. Fujimoto \\ Marquette University \\ Daniel Elliott Carey \\ Marquette University
}

Patrick J. McNamara

Marquette University, patrick.mcnamara@marquette.edu

Follow this and additional works at: https://epublications.marquette.edu/civengin_fac

Part of the Civil Engineering Commons

\section{Recommended Citation}

Fujimoto, M.; Carey, Daniel Elliott; and McNamara, Patrick J., "Metagenomics Reveal Triclosan-Induced Changes in the Antibiotic Resistome of Anaerobic Digesters" (2018). Civil and Environmental Engineering Faculty Research and Publications. 202.

https://epublications.marquette.edu/civengin_fac/202 
Marquette University

\section{e-Publications@Marquette}

\section{Civil, Construction and Environmental Engineering Faculty Research and Publications/College of Engineering}

This paper is NOT THE PUBLISHED VERSION; but the author's final, peer-reviewed manuscript. The published version may be accessed by following the link in the citation below.

Environmental Pollution, Vol. 241, (October, 2018): 1182-1190. DOI. This article is @ Elsevier and permission has been granted for this version to appear in e-Publications@Marquette. Elsevier does not grant permission for this article to be further copied/distributed or hosted elsewhere without the express permission from Elsevier.

\section{Contents}

Highlights

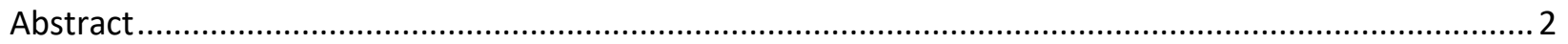

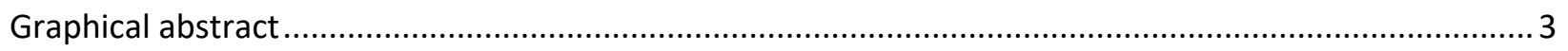

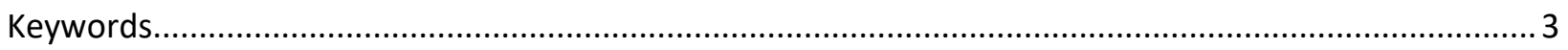

1. Introduction

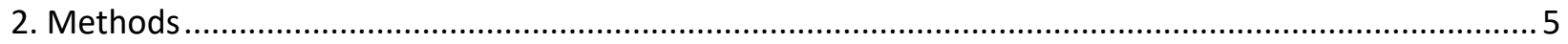

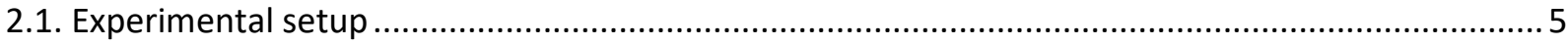

2.2. DNA extraction and shotgun metagenomics sequencing .................................................... 6

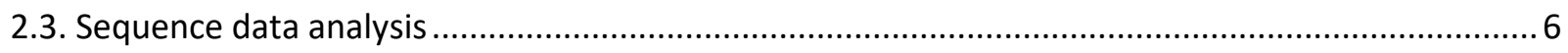

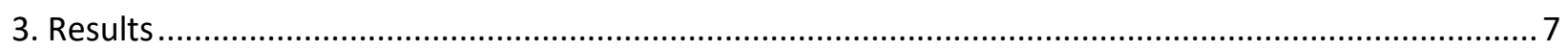

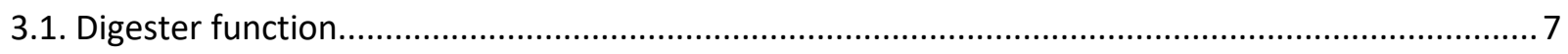

3.2. The effect of TCS concentrations on bacterial diversity and community compositions .................. 8

3.3. The effect of TCS concentrations on the antibiotic resistome ................................................. 9

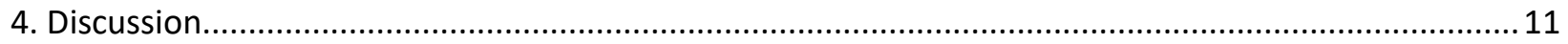

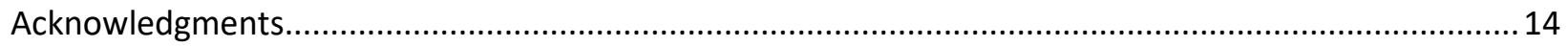

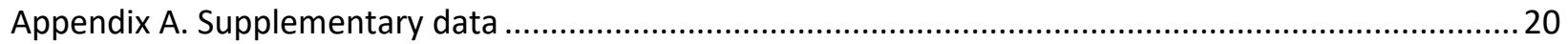

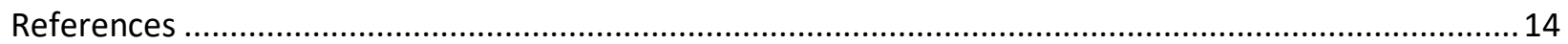




\title{
Metagenomics reveal triclosan-induced changes in the antibiotic resistome of anaerobic digesters
}

\author{
Masanori Fujimoto \\ Department of Civil, Construction and Environmental Engineering, Marquette University, \\ Milwaukee, WI \\ Soil and Water Sciences Department, University of Florida, Gainesville, FL \\ Daniel E. Carey \\ Department of Civil, Construction and Environmental Engineering, Marquette University, \\ Milwaukee, WI \\ Brown \& Caldwell, Charlotte, NC \\ Patrick J. McNamara \\ Department of Civil, Construction and Environmental Engineering, Marquette University, \\ Milwaukee, WI
}

Highlights

- ARGs resistomes of anaerobic digesters were altered by TCS additions.

- The changes in the resistome were dependent on TCS concentration.

- Previously known ARGs, including fabV, were enriched under the highest TCS concentration.

- Shotgun metagenomics revealed novel genes potentially involved in TCS resistance.

- Novel genes include metal resistance genes, transporters, and mobile elements.

\section{Abstract}

Triclosan (TCS) is a broad-spectrum antimicrobial used in a variety of consumer products. While it was recently banned from hand soaps in the US, it is still a key ingredient in a top-selling toothpaste. TCS is a hydrophobic micropollutant that is recalcitrant under anaerobic digestion thereby resulting in high TCS concentrations in biosolids. The objective of this study was to determine the impact of TCS on the antibiotic resistome and potential cross-protection in lab-scale anaerobic digesters using shotgun metagenomics. It was hypothesized that metagenomics would reveal selection for antibiotic resistance genes (ARGs) not previously found in pure culture studies or mixed-culture studies using targeted qPCR. In this study, four different levels of TCS were continuously fed to triplicate lab-scale anaerobic digesters to assess the effect of TCS levels on the antibiotic resistance gene profiles (resistome). Blasting 
metagenomic reads against antibiotic/metal resistance gene database (BacMet) revealed that ARG diversity and abundance changed along the TCS concentration gradient. While loss of bacterial diversity and digester function were observed in the digester treated with the highest TCS concentration, FabV, which is a known TCS resistance gene, increased in this extremely high TCS environment. The abundance of several other known ARG or metal resistance genes (MRGs), including corA and arsB, also increased as the concentrations of TCS increased. Analysis of other functional genes using SEED database revealed the increase of potentially key genes for resistance including different types of transporters and transposons. These results indicate that antimicrobials can alter the abundance of multiple resistance genes in anaerobic digesters even when function (i.e. methane production) is maintained. This study also suggests that enriched ARGs could be released into environments with biosolids land application.

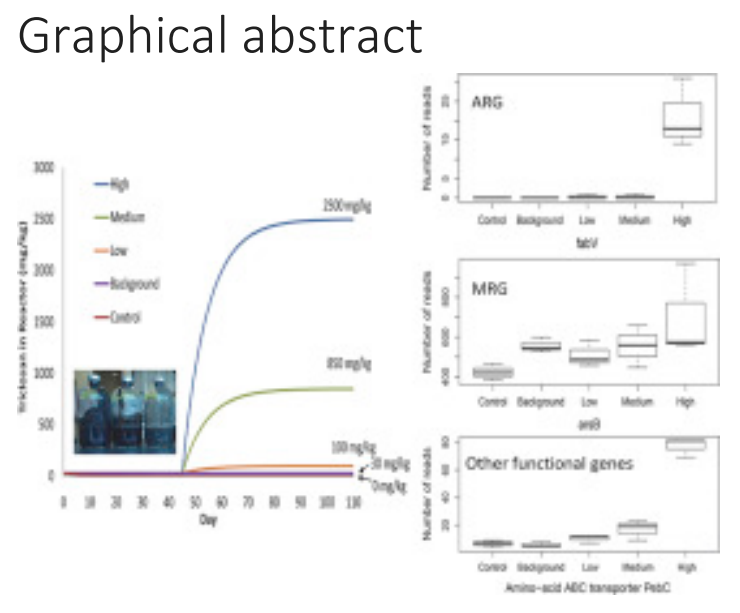

Keywords

Antibiotic resistance genes; Anaerobic digestion; Antimicrobial; Biosolids; Shotgun metagenomics

\section{Introduction}

In the United States alone over 20,000 deaths annually are attributed to infections caused by antibiotic resistance bacteria, and the associated health costs are over one billion dollars ( $\underline{C D C}, 2013)$. The Centers for Disease Control and Prevention (CDC) warns that we may soon enter a post-antibiotic era where antibiotics are no longer effective. Every year approximately 260 million prescriptions of antibiotics were provided for outpatients to treat infections in the United States from 2006 to 2010 (Suda et al., 2014), while significantly higher amount of antibiotics (accounting for nearly $80 \%$ of all antibiotic consumptions) have been used for animal husbandry (Van Boeckel et al., 2015). The paradox underlying antibiotic usage is that the more they are used the less effective they become (Levy, 2013; Barbosa and Levy, 2000; Levy and Marshall, 2004). Antibiotic resistance is indeed a natural process, in part because microbes antagonistically interact against one another in a community to compete for resources and spaces (Martínez, 2008; Fujimoto et al., 2017).

Anthropogenic activities, however, have generated more sources for dissemination of antibiotic resistance into the environment and stressors for selection of antibiotic resistance. Sources include hospital wastewater (Timraz et al., 2017), manure application (Munir and Xagoraraki, 2011; Fahrenfeld et al., 2014), agricultural runoff (Fahrenfeld et al., 2014), and wastewater treatment plants, including 
both the liquid and solid effluents (LaPara et al., 2011; Munir et al., 2011; Ju et al., 2016; Mao et al., 2015; Rizzo et al., 2013; Ma et al., 2011). During wastewater treatment processes, antibiotic resistance genes could be horizontally transferred via conjugation of plasmids and/or other mobile elements in genomes (Rizzo et al., 2013). Furthermore, many antibiotics are recalcitrant to wastewater treatment processes and are released into environments without being degraded (Levy and Marshall, 2004). Other chemical stressors including metals (Baker-Austin et al., 2006) and antimicrobials (Carey and McNamara, 2016) have also been linked to selection for antibiotic resistance. Note that the term 'antibiotic' is used to describe compounds (typically derived from microorganisms) used for clinical purposes to treat bacterial infections (e.g. vancomycin). Antimicrobial is a broader term encompassing all chemicals that inhibit growth of microorganisms. Antibiotics are thus a subset of antimicrobials, but we use the term antibiotic to note when we are specifically referring to clinically-relevant drugs. Accumulation of antibiotics and antimicrobials in water and soil could alter microbial communities in environments (Johnson et al., 2009) and thus potentially affect natural biogeochemical processes that are mediated by microbes. Increased stressors in water and soils and subsequent selection for ARGs in natural environments may also pose threat to public health as human pathogens may acquire resistance (Martínez, 2008).

Triclosan (TCS) is a broad-spectrum antimicrobial that is a stressor for antibiotic resistance and is widely found in the environment including surface water, soil and sediments (Carey and McNamara, 2015). TCS has been used in a wide variety of consumer products for decades including hand soaps and toothpaste (Macri, 2017). In 2017, the FDA finalized the rule that banned over-the-counter hand soaps that contained TCS, in part because TCS was linked to antibiotic resistance (USFDA, 2016; McNamara and Levy, 2016). Even with the ban, TCS will still be prevalent as it is a key ingredient in one of the top selling toothpastes (Macri, 2017). The widespread use of TCS has resulted in its widespread detection throughout the environment, leading to concern for widespread selection of environmental antibiotic resistance (Carey and McNamara, 2015; Chalew and Halden, 2009).

While TCS has been used as a broad-spectrum antimicrobial, the sensitivity to TCS varies across microorganisms (Russell, 2003). A specific genetic target of TCS was previously identified in genus Escherichia (McMurry et al., 1998; Levy et al., 1999). In E.coli, TCS targets fatty acid biosynthesis by inhibiting function of the fabl (enoyl-acyl-carrier protein reductase) gene (McMurry et al., 1998; Levy et al., 1999). Escherichia and some other gammaproteobacteria genera acquire resistance to TCS through mutation of fabl (Brenwald and Fraise, 2003), expression of fabK (Heath and Rock, 2000) or fabV (Zhu et al., 2010), isoenzymes of fabl, or through efflux pumps including mex genes (Chuanchuen et al., 2001). Non-specific mechanisms including expression of transporters were also suggested to contribute to resistance to TCS (Tkachenko et al., 2007; Yu et al., 2010). While the target of TCS have been primarily studied in genera within gamma-proteobacteria, targets of TCS in other phyla including Firmicutes remain unknown (Heath and Rock, 2000). Archaea has distinct fatty acid synthesis mechanisms from bacteria (Lombard et al., 2012), thus the target(s) of TCS presumably differ from bacterial lineage. A major concern surrounding TCS resistance is that bacteria exposed to TCS can develop resistance to other clinically important antibiotics (i.e. cross-protection) including ciprofloxacin (Chuanchuen et al., 2001; Braoudaki and Hilton, 2004) and other antibiotics (Carey and McNamara, 2015; Braoudaki and Hilton, 2004; Middleton and Salierno, 2013). Although many studies on TCS and antibiotic resistance mechanisms have been conducted on pure cultures (Chuanchuen et al., 2001; Braoudaki and Hilton, 2004; Pycke et al., 2010a; Pycke et al., 2010b; Chuanchuen et al., 2003), the 
impact of TCS on antibiotic resistance in mixed microbial communities is of great importance for understanding the potential impacts of this broad-spectrum antimicrobial on the spread of antibiotic resistance, particularly in anaerobic digesters where TCS is most likely to pass through due to its hydrophobic nature and recalcitrance under anaerobic conditions (Ying et al., 2007; McNamara and Krzmarzick, 2013; Pycke et al., 2014; Heidler and Halden, 2008). Furthermore, over half of biosolids in the United States are land applied providing a direct route into the environment (Gude, 2015).

Few studies have investigated the role of TCS on ARGs in anaerobic digesters. To the best of our knowledge, no research has employed metagenomic analysis to determine the impact of TCS on the antibiotic resistome in anaerobic digestion. Previous work revealed that TCS selected for $\operatorname{mex} B, \mathrm{a}$ multidrug efflux pump, in anaerobic digesters seeded with manure (McNamara et al., 2014) and municipal biosolids (Carey et al., 2016). These studies employed quantitative PCR (qPCR) which limits the scope of genes that can be found, as qPCR uses primers that target specific genes of interest. A recent study investigating the impact of TCS on the soil microbiome using fosmid clone library revealed multiple resistance mechanisms to TCS (Khan et al., 2016), indicating that the impacts of TCS on the antibiotic resistome in anaerobic digesters could be far greater than previously revealed by targeted research. A more comprehensive metagenomics approach needs to be employed to determine the impact of TCS on the antibiotic resistome in mixed microbial communities, specifically anaerobic digesters.

The objective of this research was to determine the effect of different TCS concentrations on the antibiotic resistome in anaerobic digestion. Laboratory-scale anaerobic digesters were continuously fed with TCS at levels ranging from background concentrations found in the seed biosolids to an order of magnitude higher than the maximum concentration found in biosolids. Metagenomic analysis was employed to characterize the antibiotic resistome. Based on anaerobic digesters having diverse microbial communities, it was hypothesized that resistance to TCS could be acquired through different mechanisms and that the response of the antibiotic resistomes would reveal resistance mechanisms not previously found in pure culture studies and mixed culture studies with targeted qPCR. It was also hypothesized that genes contributing to TCS resistance would have positive correlations between their abundance and TCS concentrations.

\section{Methods}

\subsection{Experimental setup}

Triplicate lab-scale anaerobic digesters were operated as previously described (Carey et al., 2016). Briefly, digesters ( $160 \mathrm{~mL}$ serum bottles with $50 \mathrm{~mL}$ active volume) were inoculated with biomass from full-scale anaerobic digesters at South Shore Water Reclamantion Facility (Oak Creek, WI, USA). The digesters had a 10-day solids retention time (SRT). Digesters were fed semi-continuously in a batch reactor, where $5 \mathrm{~mL}$ of sludge was removed every day and $5 \mathrm{~mL}$ of synthetic primary sludge consisting of dried dog food and nutrient media was added. The chemical oxygen demand (COD) loading rate was $3.6 \mathrm{~g} \mathrm{COD} /\left(\mathrm{L}_{\mathrm{r}}\right.$-day). Digesters were mixed on a shaker table at $100 \mathrm{rpm}$ and were operated at $35^{\circ} \mathrm{C}$.

Five sets of triplicate digesters were operated at the following target concentrations: i) "background" that was fed $30 \mathrm{mg} / \mathrm{kg}$ TCS for the duration of the experiment (equivalent to TCS concentration found in seed biomass in mg TCS per kg dry biosolids), ii) "low" fed at $100 \mathrm{mg} / \mathrm{kg}$, iii) "medium" fed at $850 \mathrm{mg} / \mathrm{kg}$, iv) "high" fed at $2500 \mathrm{mg} / \mathrm{kg}$, and v) a control set that was not fed any TCS. In a 2001 study by the EPA, 
the highest TCS concentration detected in biosolids was $133 \mathrm{mg} / \mathrm{kg}$ (mg TCS per kg dry biosolids) (EPA, 2001). Thus, the background and low sets represent environmentally relevant concentrations, the medium set was approximately 6 -fold higher than the maximum environmental concentration, and the high set was an order of magnitude greater than the maximum measured environmental concentration. For the first 45 days, digester sets i-iv were fed the background level. On Day 46, the TCS concentration in the feed was changed to the target concentration; the target concentrations were achieved by approximately Day 75, or 3 SRT values. Five $\mathrm{mL}$ of sludge samples were collected on Day 110 when the digesters had been receiving their designated TCS concentration for more than 3 SRT values. Out of $5 \mathrm{~mL}, 1.8 \mathrm{~mL}$ were used for DNA analysis. Gas production in headspace was measured using a $150 \mathrm{~mL}$ wetted syringe and methane content was determined using a gas chromatography (7890A, Angilent Technologies, Santa Clara, CA) (see detailed procedures in Carey et al., 2016).

\subsection{DNA extraction and shotgun metagenomics sequencing}

Genomic DNA was extracted via MP FastDNA SPIN kits (Solon, Ohio) with a minor modification that included three freeze-thaw cycles (McNamara et al., 2014). The concentrations of the extracted DNA were measured using NanoDrop Lite Spectrophotometer (Thermo-Fisher Scientific, MA), a compact version of NanoDrop 2000/2000C (Desjardins and Conklin, 2010), and were sent to a sequencing facility at the Research Technology Supporting Facility (RTSF) in Michigan State University after adjusting the concentrations to $10 \mathrm{ng} / \mu \mathrm{l}$ by diluting with DNase free water. Shotgun metagenomics library was prepared using TruSeq Nano DNA Library Preparation Kit (illumine, CA) with insertion size of approximately 550bp long at the RTSF. Adapter sequences were ligated and purified according to the TruSeq Nano DNA Library Preparation Kit protocol (Illumina, 2015). The concentration of each library was measured using Qubit and Kapa Library Quantification qPCR and libraries were pooled in equimolar amounts. Sequencing was performed using the Illumina HiSeq 2500 Rapid Run Flow Cell in $2 \times 150$ paired end format with dual lane loading. The sequencing of the same library pool was repeated with a single lane to generate more sequence reads. The raw read data were demultiplexed and converted to fastq format.

\subsection{Sequence data analysis}

The fastq outputs of the short sequence reads from the three lanes were concatenated using "zcat" command in linux for each direction. The concatenated sequence reads data from both directions of 15 samples were submitted to MG-RAST (Argonne National Laboratory) (Meyer et al., 2008) for initial processing that removed low quality or duplicate reads. The submitted metagenomics reads were deposited in MG-RAST database under the project name "Anaerobic Digester Triclosan". For antibiotic resistome analysis, the first 12 million reads of the quality reads from single direction of each sample were selected using a custom command in linux (to minimize the reads bias on antibiotic gene abundance across samples) and were blasted against antibiotic resistance genes (ARG) and metal resistance genes (MRG) database using BacMet (Pal et al., 2013). The output antibiotic resistome matrix from BacMet was used to create a PCoA plot with Bray-Curtis distance. ANOSIM was performed to assess the significance of clustering using vegan package with Bray-Curtis distance in $R$ ( $\underline{R}$ Core Team, 2013). ARGs or MRGs that increased their abundance along the TCS concentration gradient were screened using pairwise comparisons against the control group in STAMP (Parks et al., 2014) with White non-parametric test (White et al., 2009). ARGs or MRGs that had $P$ values less than 0.05 in any of the pairwise comparisons against the control group were considered statistically significant in this screening process. 
For ribosomal RNA gene analysis, all quality reads that passed through the initial quality control processing in MG-RAST were further processed for gene annotations in MG-RAST. The ribosomal RNA gene detection was performed using vsearch (Rognes et al., 2016) with the subset of Silva (Pruesse et al., 2007), Greengene (DeSantis et al., 2006) and RDP (Cole et al., 2003) combined database. For those reads that were identified as $16 \mathrm{~S}$ rRNA gene, the short reads were clustered at $97 \%$ sequence similarity using cd-hit (Fu et al., 2012), and taxonomy of the clustered reads (represented by the longest read in a cluster) were determined using BLAT algorithm (Kent, 2002) with the Silva, Greengene and RDP combined database in MG-RAST. The obtained taxa-abundance matrix was rarefied in R using "rrarefy" function in vegan package, and a PCoA plot was generated in R using "ggplot" function with the BrayCurtis distance of the rarefied matrix. ANOSIM was performed in R with Bray-Curtis distance using vegan package to evaluate whether the observed clustering was by chance or statistically significant.

For functional gene analysis, the quality reads were subjected to FragGeneScan (Rho et al., 2010) to predict the Open Reading Frames (ORFs). The function and taxonomic identity of the predicted ORFs were annotated using $\mathrm{m} 5 \mathrm{nr}$ database (Wilke et al., 2012) in MG-RAST. A rarefaction curve that depicts the relationship between the number of reads and species counts (based on the gene annotation using $\mathrm{m} 5 \mathrm{nr}$ database) was generated. Species counts were compared across different TCS levels after rarefying metagenomic reads at 10 million using the rarefaction curve. ANOVA followed by post hoc multiple comparisons with Tukey correction was performed using TukeyHSD function with an aov model in $\mathrm{R}$ to assess the difference in species counts across the TCS gradients. The abundance profile of the functional genes were also generated with SEED subsystems approach (Overbeek et al., 2013) in MGRAST. The abundance profile was rarefied in R using "rrarefy" function in vegan package. The abundance of the annotated functional genes was examined for the positive responses to increased TCS concentrations. The abundance of the annotated functional genes in each TCS level was compared to that in the control group using STAMP with Welch's unequal variance test (Ruxton, 2006). The functional genes with $P$ values less than 0.01 (stringent cut-off level) in any of the comparisons against control group were considered responding positively to the TCS concentrations and were plotted in R.

\section{Results}

\subsection{Digester function}

The main goal of this study was to determine the impact of TCS concentrations on the antibiotic resistome in anaerobic digesters. The impact of TCS concentrations on digester function was previously reported but is briefly described here because the functional health of the digesters is relevant to the discussion of microbial communities and antibiotic resistomes. In short, the control, background, low, and medium digester sets all maintained functional health, i.e. methane production was consistent, and pH was maintained near neutral (Carey et al., 2016). The TCS concentrations used in the high sets, however, resulted in essentially failed anaerobic digestion. Methane production nearly ceased and $\mathrm{pH}$ dropped to approximately 5 in all three replicates. When analyzing impacts of TCS on antibiotic resistomes it is important to note that digester sets with TCS concentrations from 0 to $850 \mathrm{mg} / \mathrm{kg}$ maintained functional health while the high set at $2500 \mathrm{mg} / \mathrm{kg}$ did not maintain functional health (Carey et al., 2016). 


\subsection{The effect of TCS concentrations on bacterial diversity and community compositions}

High TCS concentrations affected both species richness and microbial community compositions (Fig. 1 , Fig. S1). Species richness, which is represented by species counts based on the annotation of functional genes in $\mathrm{m} 5 \mathrm{nr}$ database, was not statistically different from control through medium sets (ANOVA with post hoc, $p>0.25$ ). However, in the high TCS set, species counts dropped approximately by half (Fig. 1). The difference in the species counts between the high TCS set and all other sets was statistically significant (ANOVA with post hoc, $p<0.001$ ) when compared at the rarefied 10 million reads (Fig. 1 ), which already reached plateau in rarefaction curves (Fig. S1). The drop in species counts is attributed to the lower tolerance of many microbial taxa to the high TCS concentrations.

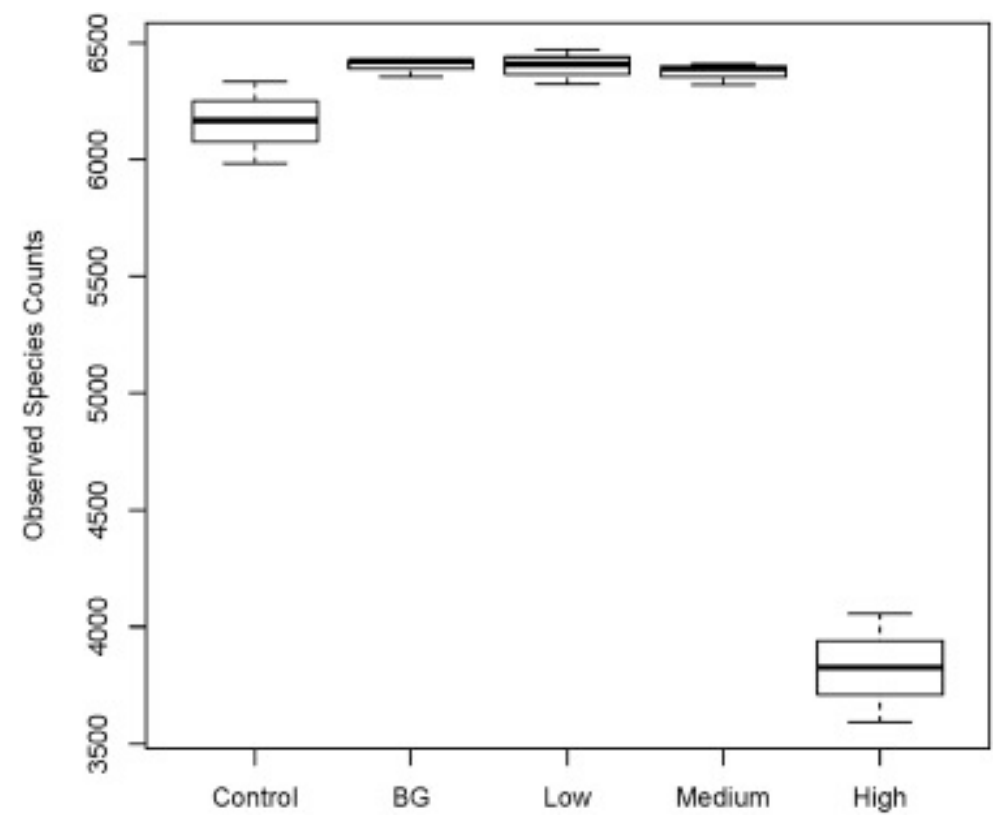

Fig. 1. Observed species counts across different TCS treatment groups rarefied at ten million reads.

Metagenomic reads that were annotated as $16 \mathrm{~S}$ ribosomal RNA in Silva, Greengene and RDP combined database were retrieved and microbial communities were compared across digester sets with different TCS concentrations. Microbial community compositions of samples treated at the high TCS concentration significantly differed from those treated with lower concentrations (Fig. 2, p = 0.004, ANOSIM). When microbial communities were examined at phylum-class level, the high TCS samples had more Bacteroidetes and less fermicutes compared to the other digester sets treated with lower TCS concentrations. Phylum Spirochaetes, Euryarcheota, and class Deltaproteobacteria also decreased in samples treated with the high TCS concentrations (Fig. S2). Loss of microbial taxa from digester microbial populations including methanogens that belong to phylum Euryarcheota and some key syntrophs that belong to deltaproteobacteria likely contributed to the loss of digester function. 


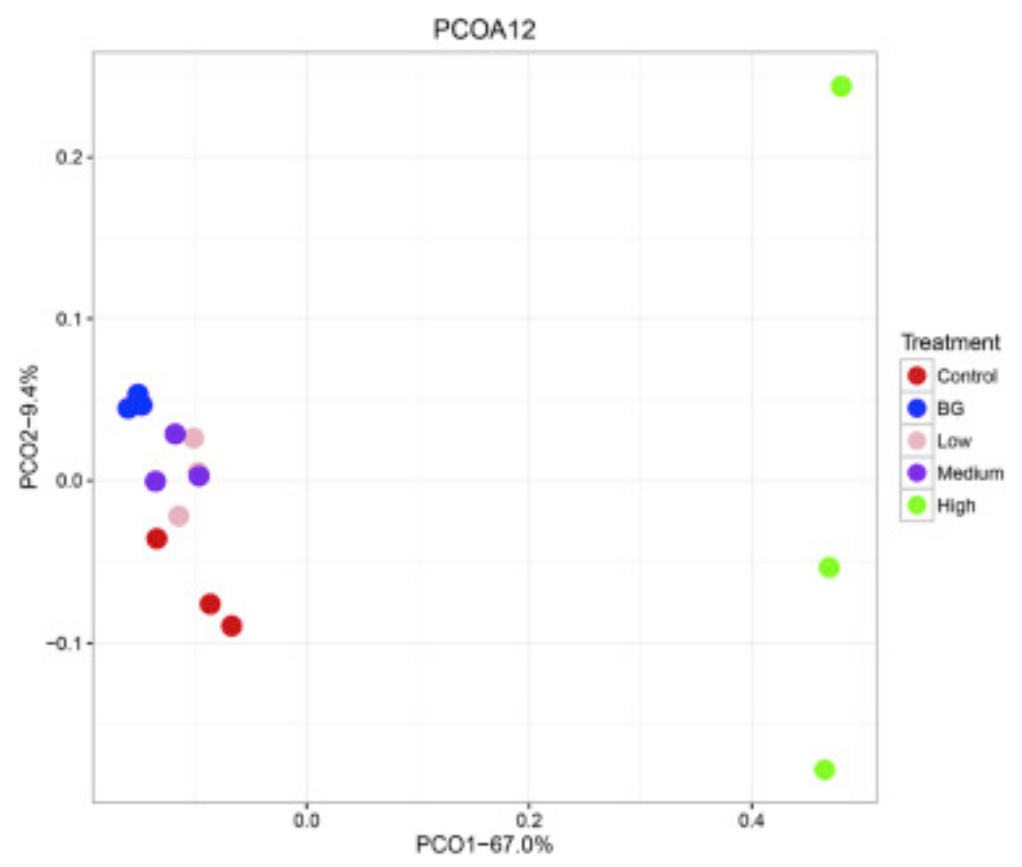

Fig. 2. PCoA plot using Bray-Curtis distance of $16 \mathrm{~S}$ rRNA annotated metagenomic reads.

\subsection{The effect of TCS concentrations on the antibiotic resistome}

The abundance of antibiotic resistance genes and metal resistance genes in each sample was assessed by blasting metagenomic reads against an ARG/MRG database (BacMet). A principal coordinates plot was generated using the BacMet output matrix with Bray-Curtis dissimilarity distance (Fig. 3 ). The resistome of digesters that were treated with the highest TCS concentration were significantly different from the rest of the samples (see the axis 1 of Fig. 3: $p=0.005$, ANOSIM). Increasing TCS doses also had an effect on resistomes as control samples were separated from background, low and medium digester sets (along the axis 2 of Fig. 3). The function of the digesters treated with background, low and medium concentrations of TCS were maintained, indicating that TCS can alter antibiotic resistomes without inhibiting function.

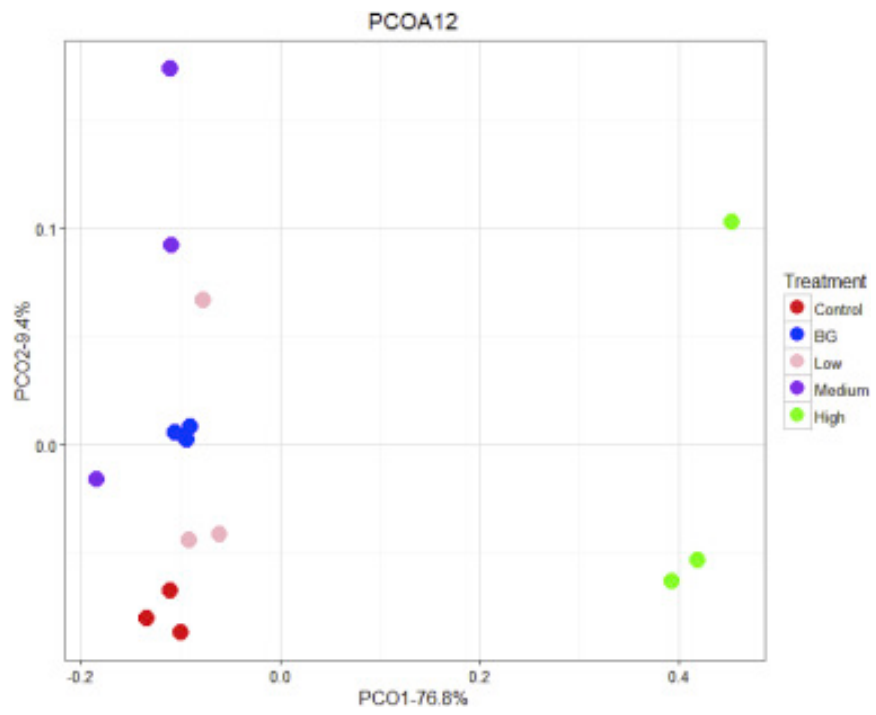


Fig. 3. PCoA resistome plot across samples treated with different concentrations of TCS.

Although the abundance of some ARGs and MRGs that were present in control digesters decreased as TCS concentration increased, the abundance of other ARGs and MRGs increased with TCS dosage. In order to identify ARGs and MRGs that contributed to resistance against TCS, ARGs and MRGs with significantly increased abundance along TCS gradients were plotted (Fig. 4). The abundance of nine ARGs or MRGs were found to increase with TCS concentrations. The patterns of increasing trend differ across ARGs and MRGs. Three different patterns were observed for how increased TCS concentrations affected the abundance of resistance genes. One was that the abundance of genes increased only when sludge samples were exposed to the highest doses (CorA and FabV). Another pattern was that gene abundance increased from the control to the highest doses (arsB). The other pattern was that the abundance of genes increased up to medium doses and collapsed at the highest doses (copA, bexA, zupT/ygiE, csoR, ziaA, and gadC/xasA).
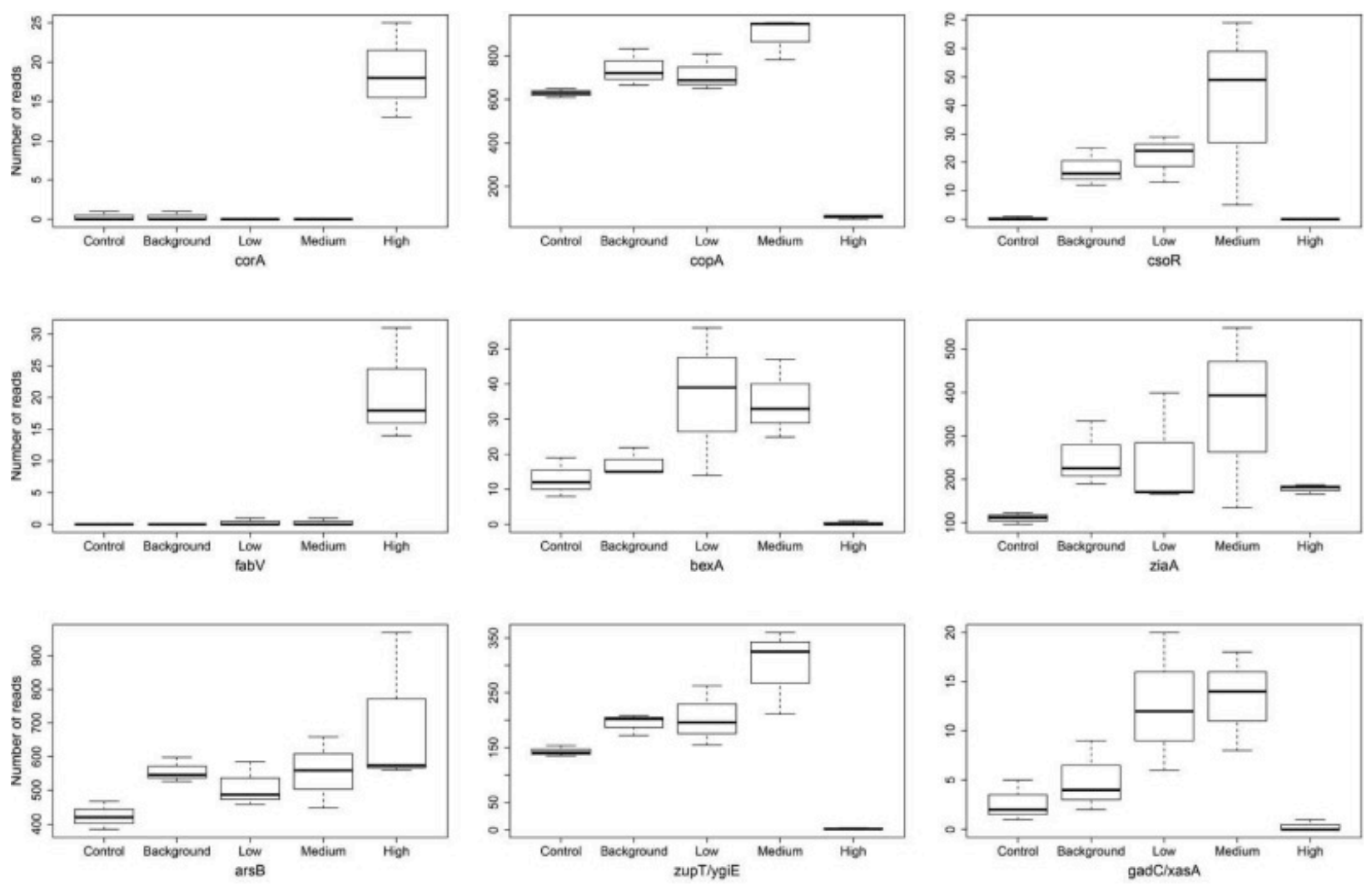

Fig. 4. Changes in ARG and MRG abundance along TCS gradients.

The possibility that other functional genes may confer resistance to TCS was examined using gene annotations with functional level of the SEED subsystems. The abundance of 75 genes was found to increase with an increase in TCS concentrations. Twenty two out of 75 genes were identified to be "transporters" which facilitate transportation of specific molecules between cell membranes. Those identified include metal transporters, nucleotide transporters, amino acid transporters, sugar transporters, and others. Genes associated with conjugative transposons including TraG, TraK, TraM and TraN were also identified to increase in abundance as TCS concentrations increased (all Tra genes increased their abundance at the highest TCS level). The abundance of a gene that encodes for an 
integrase also increased at the highest TCS level. Similar to patterns observed between ARG abundance and TCS concentrations, the increasing trends of other functional genes were also categorized into three groups. For one group, the increase in gene abundance was not observed until sludge was exposed to the highest doses (Fig. 5A). A total 31 genes followed this trend including conjugative transposon proteins and several transporter genes (Fig. S3, Panel A). As for the second group, the increase in gene abundance relative to the control was observed at background, low, and/or medium TCS concentrations, but decreased at the highest TCS concentrations (Fig. 5B). A total of 30 genes followed this pattern including several transporter genes for metals, sugars, and amino acids (Fig. S3, Panel B). The third pattern observed was that the abundance of functional genes increased as the doses of TCS increased (Fig. 5C). A total of 14 genes followed this pattern including those genes involved in transport of sugars and nucleotides (Fig. S3 Panel C).
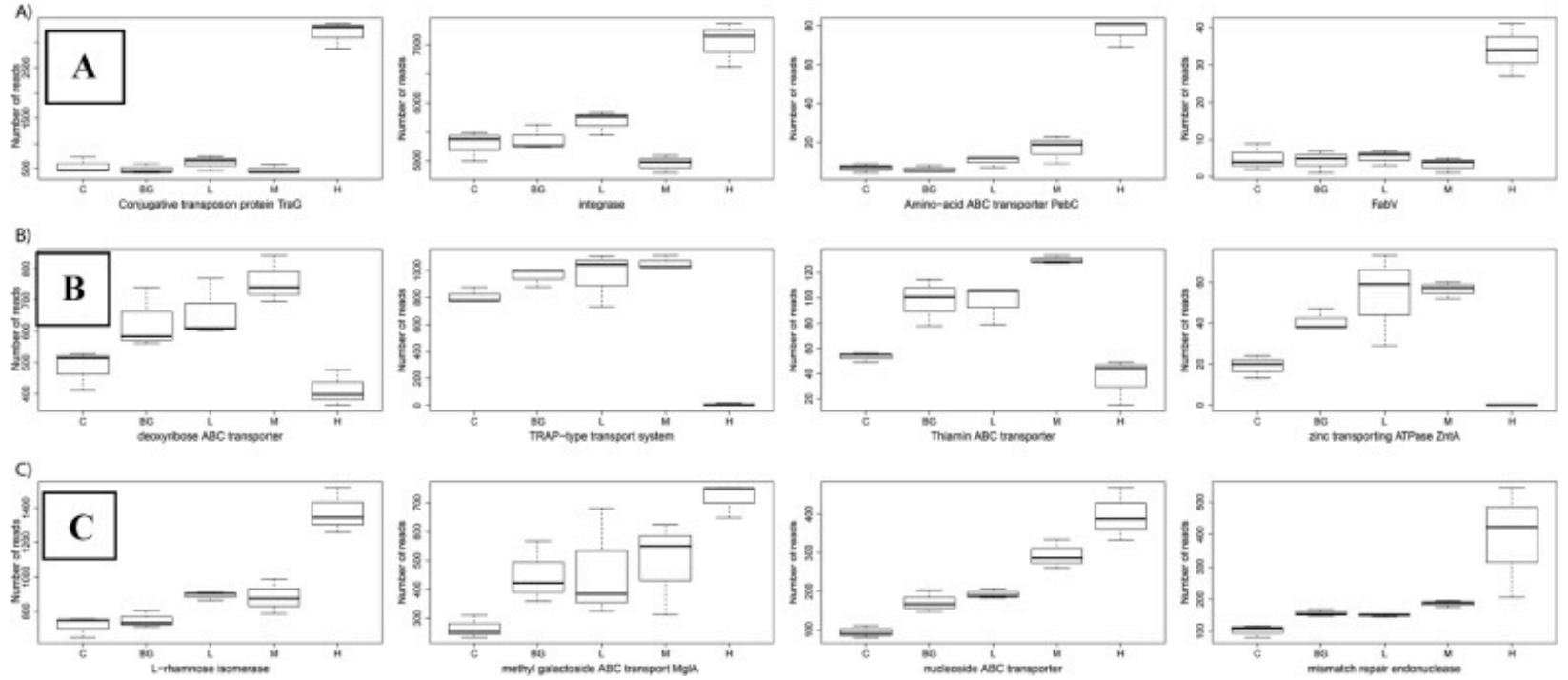

Fig. 5. Changes in abundance of other functional genes along TCS gradients. Panel A) genes that displayed steep increase in abundance at the highest TCS, B) genes that displayed gradual increase in abundance up to medium TCS, and C) genes that displayed gradual increase in abundance up to the highest TCS.

\section{Discussion}

The potential of broad-spectrum antimicrobials such as TCS to enrich ARGs in anaerobic digesters was examined in this study. Only a handful ARGs were previously known to confer resistance to TCS prior to this study. As ARGs and MRGs are known to cross-protect against a range of antibiotics and toxic metals, changes in abundance of all previously known ARGs and MRGs, according to BacMet database, were examined as a function of TCS doses in this study. While TCS is an antimicrobial affecting a range of microbial populations, we hypothesized that resistance mechanisms were also diverse. Thus, we expanded our search for resistance mechanisms to all other functional genes.

Multiple ARGs and MRGs responded to TCS in this study, including fabV that was previously known to confer resistance to TCS (Zhu et al., 2010). TCS acts on an enzyme that is involved in the cellular membrane fatty acids synthesis (Fabl), and the expression of fabV, isoenzyme of fabl, confers resistance against TCS. The abundance of fabV increased only for the high TCS digester set, suggesting that the possession of fabV allowed them to survive under the extremely high TCS concentration. Two other 
MRGs were also identified to increase in the high TCS digester set and likely confer resistance to high TCS concentrations, arsB and corA. ArsB is a metal transporter gene that facilitates transportation of metals, specifically arsenic (Shen et al., 2013). CorA is also a metal transporter that is known to transport magnesium (Kehres et al., 1998). Among all metal resistance genes in the BacMet database, corA and arsB were the only genes whose abundance increased at a level that was statistically significant when exposed to the high TCS digester set. In contrast, the abundance of other MRGs including copA (Rensing et al., 2000) and csoR (Corbett et al., 2011) for copper resistance and ziaA (Busenlehner et al., 2003) and zupT (Grass et al., 2005) for zinc resistance, increased only up to the medium TCS digester set. It remains unknown what the unique features are for corA and arsB in terms of their ability to confer resistance to the highest TCS level. Other genes identified through this process are bexA (Miyamae et al., 2001), a known multidrug resistance gene via efflux pump, and gadC, a gene expressed during stress responses including exposure to antibiotics (Händel et al., 2014; Adam et al., 2008). The abundance of mexB, a previously known resistance gene to TCS (Chuanchuen et al., 2003; Ghosh et al., 2011), also slightly increased as TCS doses increased, but not to the extent that was statistically significant ( $p>0.05$ in any pairwise comparisons relative to control). This is partly because the abundance of the mexB gene in anaerobic digesters is not substantial enough to reveal the effect of treatment relative to the control.

A possibility that other functional genes could confer resistance to TCS was explored using the SEED database. Genes that were identified to increase abundance upon exposure to TCS included various types of transporters which facilitate transportation of specific molecules across cell membranes. Those identified include metal transporters, nucleotide transporters, amino acid transporters, and sugar transporters. Although their known functions are transporting specific molecules, their machinery could have been used to remove TCS from cells. A potential role of transporters in resistance to TCS has also been reported by a previous study using Gene-Chip based RNA profiling (Tkachenko et al., 2007). It is possible that these multiple transporter genes may additively help the host microbes to survive under the high TCS environments, unlike the case of fabV where a single gene confers resistance to TCS. Alternatively, such transporter genes were potentially selected for to compensate for the loss of essential molecules released by non-specific efflux pumps together with TCS. Another group of genes that were identified to increase in gene abundance with increases in TCS concentrations was conjugative transposons. Transposon related genes could be used to mobilize some ARGs or MRGs that confer resistance to TCS (Bennett, 2008). The increased gene abundance identified at the highest TCS level could be due to the selection for microorganisms that originally housed the genes that confer resistance to TCS or such resistance genes were horizontally transferred to multiple different hosts via mobile genetic elements (conjugative plasmids, transposons and integrase) and subsequently enriched.

Although increased concentrations of TCS corresponded to increases in the abundance of several genes, the type of increasing trend varied across the genes. Some ARGs had increased abundance at background, low, and medium TCS concentrations but collapsed at the highest TCS doses. Other ARGs increased abundance gradually to the highest TCS doses, while some did not show any increases until exposed to the highest TCS doses. Genes that have a positive linear relationship with TCS from background to medium level may have had a growth advantage in the system, while taxa diversity was maintained at these TCS levels. The collapse at the highest TCS dose suggests that taxa that housed such genes were eliminated by the TCS or other environmental factors such as low pH. Genes that increased their abundance up to the highest TCS level may have had mechanisms that avoid or neutralize bacteriocidal activities of TCS or hitchhiked with the taxa that house resistance genes. Those genes that 
were flat (did not change gene abundance) until the highest TCS dose could withstand TCS challenges, but had no competitive advantage from background to medium TCS levels probably because resources and/or environments were not optimum for them to outgrow their competition. A sudden increase at the highest dose was observed because the loss of taxa in the system (depicted in Fig. 4) could indirectly increase the gene abundance of remaining taxa that house such resistance genes. The concentration that different ARGs are effective against varies by ARG as indicated by the different responses of ARGs to TCS concentrations. This differential effective range to TCS may create a complex response of microbial communities to a given concentration of TCS in environments.

Our previous study based on 16S rRNA amplicon sequencing revealed that the high TCS concentration significantly altered microbial communities (Carey et al., 2016). Furthermore the high TCS concentration resulted in the loss of digester function, including substantial reduction in methane gas production (Carey et al., 2016). This antibiotic resistomes analysis also revealed that antibiotic resistomes differ across TCS concentrations. While the largest difference in resistome was detected between the high TCS concentration and others, the differences in the resistome were also observed among controls, background, low, and medium sets even when function was maintained. The background $(30 \mathrm{mg} / \mathrm{kg})$ and low $(100 \mathrm{mg} / \mathrm{kg})$ TCS concentrations used in this study were within the environmental range of TCS concentrations found in municipal biosolids (EPA, 2009). The medium (850 mg/kg) and high $(2500 \mathrm{mg} / \mathrm{kg})$ TCS concentrations tested were out of the range that were typically found in wastewater, but corresponded to TCS doses that resulted in $10 \%$ and $50 \%$ methane gas reduction in short-term preliminary batch testing, respectively (Carey et al., 2016). As noted, the methane production observed in this present long-term study slightly differed from those obtained from preliminary batch experiments, probably due to the difference in exposure duration. The medium concentration used in this study $(850 \mathrm{mg} / \mathrm{kg}$ ) was close to the concentrations that were previously used for TCS resistance studies by other researchers $(1024 \mathrm{mg} / \mathrm{L}$ in agar plate was used by Chuanchuen et al. (Chuanchuen et al., 2003)). The highest TCS concentration used in this study $(2500 \mathrm{mg} / \mathrm{kg})$ was above the concentrations that are typically found in anaerobic digesters that were used in previous TCS resistance studies. Although anaerobic digester function represented by methane gas production was impaired at this highest TCS concentration, nearly half of microbial taxa that were initially present survived at this extremely high TCS concentration. Although the highest TCS concentration used in this study may not reflect practical conditions, the highest concentration served as a unique environment that tests the ability of microbes to resist such extreme conditions. Higher concentrations could also be found near facilities that manufacture TCS as has been found for pharmaceutical manufacturing facilities (Phillips et al., 2010).

Another limitation of this study was that we could not separate the direct effect of TCS on ARGs from the indirect effect of altered environmental conditions caused by TCS on ARGs. In the high TCS digester sets, for example, this alteration in environmental conditions included lowered $\mathrm{pH}$ which could have selected for microbes that were resistant to acidic conditions. Some of the ARGs and MRGs identified in this study may be associated with microbes that adapted to lower $\mathrm{pH}$, rather than associated with specific TCS resistance mechanisms. Although a large number of genes were identified to be more abundant at the highest TCS doses, it is reasonable to assume that not all the genes were functioned to confer resistance to TCS. While acidic $\mathrm{pH}$ was observed only in the highest TCS digester set, the abundance of several resistance genes increased from the control to the medium TCS level, where near 
neutral $\mathrm{pH}$ was maintained. Thus, changes observed in resistome within this TCS range were attributed to the direct effect of TCS on ARGs.

Overall, results indicate that the abundance of several ARGs, MRGs, transporters and mobile elements were enriched upon addition of TCS. TCS is known to have biocide effects on a wide range of microbial taxa (Bhargava and Leonard, 1996), although its known target is limited to an enzyme, Fabl, that is involved in fatty acid synthesis and is essential in maintaining cellular membrane integrity (McMurry et al., 1998). Although the resistance mechanisms to TCS were presumed to be limited, including isoenzymes (fabK and fabV) and efflux pumps, our study showed that several other MRGs and transporters could confer resistance that allow taxa to withstand extremely high TCS concentrations. This in turn indicated that a single antimicrobial could select for various resistance mechanisms that were present in the original seed microbial community, depicting a complex nature of antibiotic resistance in mixed cultures. Unlike pure culture or quantitative PCR based approach, shotgun metagenomics approach in a mixed culture revealed a diverse group of antibiotic resistance as we hypothesized as well as other genes that are potentially involved in triclosan resistance. Genes detected included previously unidentified resistance mechanisms against TCS such as metal resistance genes, various types of transporters, and mobile genetic elements.

This study also suggested that those ARGs, MRGs, and transporters enriched in digester biosolids could be released into environments with biosolids that are land applied. Although the fate of those resistance genes in TCS adapted strains in environments remains unknown, another study on clinically important ARGs suggests ARGs released in soil through livestock manure land application could be maintained for a couple of months in soil (Fahrenfeld et al., 2014). These TCS adapted strains are equipped with various efflux pumps and other transporting machineries that could protect them from other antibiotics. The release of wastewater effluents and land application of biosolids from wastewater may pose risks as TCS concentrations accumulate in sediments and soils and serve as a reservoir in selecting for ARGs in the environment. The use of TCS in toothpaste and other remaining hygiene products needs to be seriously considered by incorporating these potential negative impacts. TCS already released and accumulated in environments could pose perpetual stress and force antibiotic resistance selection in the environment.

\section{Acknowledgments}

M.F. was supported by the Marquette University Water Quality Center.

\section{References}

Adam et al., 2008 M. Adam, B. Murali, N.O. Glenn, S.S. Potter. Epigenetic inheritance based evolution of antibiotic resistance in bacteria. BMC Evol. Biol., 8 (1) (2008), p. 52 Baker-Austin et al., 2006 C. Baker-Austin, M.S. Wright, R. Stepanauskas, J. McArthur. Coselection of antibiotic and metal resistance. Trends Microbiol., 14 (4) (2006), pp. 176-182 Barbosa and Levy, 2000 T.M. Barbosa, S.B. Levy. The impact of antibiotic use on resistance development and persistence. Drug Resist. Updates, 3 (5) (2000), pp. 303-311 Bennett, $2008 \mathrm{P}$. Bennett. Plasmid encoded antibiotic resistance: acquisition and transfer of antibiotic resistance genes in bacteria. Br. J. Pharmacol., 153 (S1) (2008) Bhargava and Leonard, 1996 H. Bhargava, P.A. Leonard. Triclosan: applications and safety. Am. J. Infect. Contr., 24 (3) (1996), pp. 209-218 
Braoudaki and Hilton, 2004 M. Braoudaki, A.C. Hilton. Low level of cross-resistance between triclosan and antibiotics in Escherichia coli K-12 and E. coli 055 compared to E. coli 0157. FEMS Microbiol. Lett., 235 (2) (2004), pp. 305-309 Brenwald and Fraise, $2003 \mathrm{~N}$. Brenwald, A. Fraise. Triclosan resistance in methicillin-resistant Staphylococcus aureus (MRSA). J. Hosp. Infect., 55 (2) (2003), pp. 141-144 Busenlehner et al., 2003 L.S. Busenlehner, M.A. Pennella, D.P. Giedroc. The SmtB/ArsR family of metalloregulatory transcriptional repressors: structural insights into prokaryotic metal resistance. FEMS Microbiol. Rev., 27 (2-3) (2003), pp. 131-143

Carey and McNamara, 2015 D.E. Carey, P.J. McNamara. The impact of triclosan on the spread of antibiotic resistance in the environment. Front. Microbiol., 5 (2015), p. 780 Carey and McNamara, 2016 D.E. Carey, P.J. McNamara. Altered antibiotic tolerance in anaerobic digesters acclimated to triclosan or triclocarban. Chemosphere, 163 (2016), pp. 2226

Carey et al., 2016 D.E. Carey, D.H. Zitomer, A.D. Kappell, M.J. Choi, K.R. Hristova, P.J. McNamara. Chronic exposure to triclosan sustains microbial community shifts and alters antibiotic resistance gene levels in anaerobic digesters. Environ. Sci. Processes Impacts, 18 (8) (2016), pp. 1060-1067

CDC, 2013 CDC. Antibiotic resistance threats in the United States. 2013: Centres for Disease Control and Prevention, US Department of Health and Human Services (2013)

Chalew and Halden, 2009 T.E. Chalew, R.U. Halden. Environmental exposure of aquatic and terrestrial biota to triclosan and triclocarban. JAWRA J. Am. Water Resour. Assoc., 45 (1) (2009), pp. 4-13

Chuanchuen et al., 2001 R. Chuanchuen, K. Beinlich, T.T. Hoang, A. Becher, R.R. KarkhoffSchweizer, H.P. Schweizer. Cross-resistance between triclosan and antibiotics inPseudomonas aeruginosa is mediated by multidrug efflux pumps: exposure of a susceptible mutant strain to triclosan selects nfxB mutants overexpressing MexCD-OprJ. Antimicrob. Agents Chemother., 45 (2) (2001), pp. 428-432

Chuanchuen et al., 2003 R. Chuanchuen, R.R. Karkhoff-Schweizer, H.P. Schweizer. High-level triclosan resistance in Pseudomonas aeruginosa is solely a result of efflux. Am. J. Infect. Contr., 31 (2) (2003), pp. 124-127

Cole et al., 2003 J.R. Cole, B. Chai, T.L. Marsh, R.J. Farris, Q. Wang, S. Kulam, S. Chandra, D.M. McGarrell, T.M. Schmidt, G.M. Garrity. The Ribosomal Database Project (RDP-II): previewing a new autoaligner that allows regular updates and the new prokaryotic taxonomy. Nucleic Acids Res., 31 (1) (2003), pp. 442-443

Corbett et al., 2011 D. Corbett, S. Schuler, S. Glenn, P.W. Andrew, J.S. Cavet, I.S. Roberts. The combined actions of the copper-responsive repressor CsoR and copper-metallochaperone CopZ modulate CopA-mediated copper efflux in the intracellular pathogen Listeria monocytogenes. Mol. Microbiol., 81 (2) (2011), pp. 457-472

DeSantis et al., 2006 T.Z. DeSantis, P. Hugenholtz, N. Larsen, M. Rojas, E.L. Brodie, K. Keller, T. Huber, D. Dalevi, P. Hu, G.L. Andersen. Greengenes, a chimera-checked 16S rRNA gene database and workbench compatible with ARB. Appl. Environ. Microbiol., 72 (7) (2006), pp. 5069-5072

Desjardins and Conklin, 2010 P. Desjardins, D. Conklin. NanoDrop microvolume quantitation of nucleic acids. JoVE, 45 (2010), p. 2565 
EPA, 2009 U. EPA. Targeted National Sewage Sludge Survey Sampling and Analysis Technical Report. US Environmental Protection Agency Office of Water, Washington, DC (2009) Fahrenfeld et al., 2014 N. Fahrenfeld, K. Knowlton, L.A. Krometis, W.C. Hession, K. Xia, E. Lipscomb, K. Libuit, B.L. Green, A. Pruden. Effect of manure application on abundance of antibiotic resistance genes and their attenuation rates in soil: field-scale mass balance approach. Environ. Sci. Technol., 48 (5) (2014), pp. 2643-2650

Fu et al., 2012 L. Fu, B. Niu, Z. Zhu, S. Wu, W. Li. CD-HIT: accelerated for clustering the nextgeneration sequencing data. Bioinformatics, 28 (23) (2012), pp. 3150-3152

Fujimoto et al., 2017 M. Fujimoto, B. Lovett, R. Angoshtari, P. Nirenberg, T. Loch, K. Scribner, T. Mars. Antagonistic interactions and biofilm forming capabilities among bacterial strains isolated from the egg surfaces of lake sturgeon (Acipenser fulvescens). Microb. Ecol. (2017), pp. 1-16

Ghosh et al., 2011 S. Ghosh, C.M. Cremers, U. Jakob, N.G. Love. Chlorinated phenols control the expression of the multidrug resistance efflux pump MexAB-OprM in Pseudomonas aeruginosa by interacting with NaIC. Mol. Microbiol., 79 (6) (2011), pp. 1547-1556

Grass et al., 2005 G. Grass, S. Franke, N. Taudte, D.H. Nies, L.M. Kucharski, M.E. Maguire, C. Rensing. The metal permease ZupT from Escherichia coli is a transporter with a broad substrate spectrum. J. Bacteriol., 187 (5) (2005), pp. 1604-1611

Gude, 2015 V.G. Gude. Energy positive wastewater treatment and sludge management.

Editorium J. Waste Manag., 1 (2015), pp. 10-15

Händel et al., 2014 N. Händel, J.M. Schuurmans, Y. Feng, S. Brul, B.H. ter Kuile. Interaction between mutations and regulation of gene expression during development of de novo antibiotic resistance. Antimicrob. Agents Chemother., 58 (8) (2014), pp. $4371-4379$ Heath and Rock, 2000 R.J. Heath, C.O. Rock. erratum: a triclosan-resistant bacterial enzyme. Nature, 406 (6798) (2000), p. 848

Heidler and Halden, $2008 \mathrm{~J}$. Heidler, R.U. Halden. Meta-analysis of mass balances examining chemical fate during wastewater treatment. Environ. Sci. Technol., 42 (17) (2008), pp. 63246332

Illumina, 2015 Illumina. TruSeq Nano DNA Library Prep Reference Guide. (2015) FC-1219010DOC

Johnson et al., 2009 D.R. Johnson, K. Czechowska, N. Chèvre, V. Der Meer, J. Roelof. Toxicity of triclosan, penconazole and metalaxyl on Caulobacter crescentus and a freshwater microbial community as assessed by flow cytometry. Environ. Microbiol., 11 (7) (2009), pp. 1682-1691 Ju et al., 2016 F. Ju, B. Li, L. Ma, Y. Wang, D. Huang, T. Zhang. Antibiotic resistance genes and human bacterial pathogens: co-occurrence, removal, and enrichment in municipal sewage sludge digesters. Water Res., 91 (2016), pp. 1-10

Kehres et al., 1998 D.G. Kehres, C.H. Lawyer, M.E. Maguire. The CorA magnesium transporter gene family. Microb. Comp. Genom., 3 (3) (1998), pp. 151-169

Kent, 2002 W.J. Kent. BLAT-the BLAST-like alignment tool. Genome Res., 12 (4) (2002), pp. 656-664

Khan et al., 2016 R. Khan, H.G. Kong, Y.-H. Jung, J. Choi, K.-Y. Baek, E.C. Hwang, S.-W. Lee. Triclosan resistome from metagenome reveals diverse enoyl acyl Carrier protein reductases and selective enrichment of triclosan resistance genes. Sci. Rep., 6 (2016), p. 32322 
LaPara et al., 2011 T.M. LaPara, T.R. Burch, P.J. McNamara, D.T. Tan, M. Yan, J.J. Eichmiller. Tertiary-treated municipal wastewater is a significant point source of antibiotic resistance genes into Duluth-Superior Harbor. Environ. Sci. Technol., 45 (22) (2011), pp. 9543-9549 Levy, 2013 S.B. Levy. The Antibiotic Paradox: How Miracle Drugs Are Destroying the Miracle. Springer (2013)

Levy and Marshall, 2004 S.B. Levy, B. Marshall. Antibacterial resistance worldwide: causes, challenges and responses. Nat. Med., 10 (12s) (2004), p. S122

Levy et al., 1999 C.W. Levy, A. Roujeinikova, S. Sedelnikova, P.J. Baker, A.R. Stuitje, A.R. Slabas, D.W. Rice, J.B. Rafferty. Molecular basis of triclosan activity. Nature, 398 (6726) (1999), pp. 383-384

Lombard et al., 2012 J. Lombard, P. López-García, D. Moreira. An ACP-independent fatty acid synthesis pathway in archaea: implications for the origin of phospholipids. Mol. Biol. Evol., 29 (11) (2012), pp. 3261-3265

Ma et al., 2011 Y. Ma, C.A. Wilson, J.T. Novak, R. Riffat, S. Aynur, S. Murthy, A. Pruden. Effect of various sludge digestion conditions on sulfonamide, macrolide, and tetracycline resistance genes and class I integrons. Environ. Sci. Technol., 45 (18) (2011), pp. 7855-7861

Macri, 2017 D. Macri. Worldwide use of triclosan: can dentistry do without this antimicrobial? Contemp. Clin. Dent., 8 (1) (2017), p. 7

Mao et al., 2015 D. Mao, S. Yu, M. Rysz, Y. Luo, F. Yang, F. Li, J. Hou, Q. Mu, P. Alvarez.

Prevalence and proliferation of antibiotic resistance genes in two municipal wastewater . treatment plants. Water Res., 85 (2015), pp. 458-466

Martínez, 2008 J.L. Martínez. Antibiotics and antibiotic resistance genes in natural environments. Science, 321 (5887) (2008), pp. 365-367

McMurry et al., 1998 L.M. McMurry, M. Oethinger, S.B. Levy. Triclosan targets lipid synthesis. Nature, 394 (6693) (1998), pp. 531-532

McNamara and Krzmarzick, 2013 P.J. McNamara, M.J. Krzmarzick. Triclosan enriches for Dehalococcoides-like Chloroflexi in anaerobic soil at environmentally relevant concentrations. FEMS Microbiol. Lett., 344 (1) (2013), pp. 48-52

McNamara and Levy, 2016 P.J. McNamara, S.B. Levy. Triclosan: an instructive tale. Antimicrob. Agents Chemother., 60 (12) (2016), pp. 7015-7016

McNamara et al., 2014 P.J. McNamara, T.M. LaPara, P.J. Novak. The impacts of triclosan on anaerobic community structures, function, and antimicrobial resistance. Environ. Sci. Technol., 48 (13) (2014), pp. 7393-7400

Meyer et al., 2008 F. Meyer, D. Paarmann, M. D'Souza, R. Olson, E.M. Glass, M. Kubal, T. Paczian, A. Rodriguez, R. Stevens, A. Wilke. The metagenomics RAST server-a public resource for the automatic phylogenetic and functional analysis of metagenomes. BMC Bioinf., 9 (1) (2008), p. 386

Middleton and Salierno, 2013 J.H. Middleton, J.D. Salierno. Antibiotic resistance in triclosan tolerant fecal coliforms isolated from surface waters near wastewater treatment plant outflows (Morris County, NJ, USA). Ecotoxicol. Environ. Saf., 88 (2013), pp. 79-88 Miyamae et al., 2001 S. Miyamae, O. Ueda, F. Yoshimura, J. Hwang, Y. Tanaka, H. Nikaido. A MATE family multidrug efflux transporter pumps out fluoroquinolones in Bacteroides thetaiotaomicron. Antimicrob. Agents Chemother., 45 (12) (2001), pp. 3341-3346 
Munir and Xagoraraki, 2011 M. Munir, I. Xagoraraki. Levels of antibiotic resistance genes in manure, biosolids, and fertilized soil. J. Environ. Qual., 40 (1) (2011), pp. 248-255

Munir et al., 2011 M. Munir, K. Wong, I. Xagoraraki. Release of antibiotic resistant bacteria and genes in the effluent and biosolids of five wastewater utilities in Michigan. Water Res., 45 (2) (2011), pp. 681-693

$\underline{\text { R Core Team, } 2013}$ R Core Team. R: a Language and Environment for Statistical Computing. (2013)

Overbeek et al., 2013 R. Overbeek, R. Olson, G.D. Pusch, G.J. Olsen, J.J. Davis, T. Disz, R.A. Edwards, S. Gerdes, B. Parrello, M. Shukla. The seed and the Rapid annotation of microbial genomes using subsystems Technology (RAST). Nucleic Acids Res., 42 (D1) (2013), pp. D206D214

Pal et al., 2013 C. Pal, J. Bengtsson-Palme, C. Rensing, E. Kristiansson, D.J. Larsson. BacMet: antibacterial biocide and metal resistance genes database. Nucleic Acids Res., 42 (D1) (2013), pp. D737-D743

Parks et al., 2014 D.H. Parks, G.W. Tyson, P. Hugenholtz, R.G. Beiko. STAMP: statistical analysis of taxonomic and functional profiles. Bioinformatics, 30 (21) (2014), pp. 3123-3124 Phillips et al., 2010 P.J. Phillips, S.G. Smith, D. Kolpin, S.D. Zaugg, H.T. Buxton, E.T. Furlong, K. Esposito, B. Stinson. Pharmaceutical formulation facilities as sources of opioids and other pharmaceuticals to wastewater treatment plant effluents. Environ. Sci. Technol., 44 (13) (2010), pp. 4910-4916

Pruesse et al., 2007 E. Pruesse, C. Quast, K. Knittel, B.M. Fuchs, W. Ludwig, J. Peplies, F.O. Glöckner. SILVA: a comprehensive online resource for quality checked and aligned ribosomal RNA sequence data compatible with ARB. Nucleic Acids Res., 35 (21) (2007), pp. 7188-7196 Pycke et al., 2010a B.F. Pycke, A. Crabbé, W. Verstraete, N. Leys. Characterization of triclosanresistant mutants reveals multiple antimicrobial resistance mechanisms in Rhodospirillum rubrum S1H. Appl. Environ. Microbiol., 76 (10) (2010), pp. 3116-3123

Pycke et al., 2010b B.F. Pycke, G. Vanermen, P. Monsieurs, H. De Wever, M. Mergeay, W. Verstraete, N. Leys. Toxicogenomic response of Rhodospirillum rubrum S1H to the micropollutant triclosan. Appl. Environ. Microbiol., 76 (11) (2010), pp. 3503-3513 Pycke et al., 2014 B.F. Pycke, I.B. Roll, B.J. Brownawell, C.A. Kinney, E.T. Furlong, D.W. Kolpin, R.U. Halden. Transformation products and human metabolites of triclocarban and triclosan in sewage sludge across the United States. Environ. Sci. Technol., 48 (14) (2014), pp. 7881-7890 Rensing et al., 2000 C. Rensing, B. Fan, R. Sharma, B. Mitra, B.P. Rosen. CopA: an Escherichia coli Cu (I)-translocating P-type ATPase. Proc. Natl. Acad. Sci. Unit. States Am., 97 (2) (2000), pp. 652 656

Rho et al., 2010 M. Rho, H. Tang, Y. Ye. FragGeneScan: predicting genes in short and errorprone reads. Nucleic Acids Res., 38 (20) (2010), p. e191

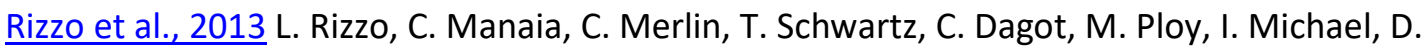
Fatta-Kassinos. Urban wastewater treatment plants as hotspots for antibiotic resistant bacteria and genes spread into the environment: a review. Sci. Total Environ., 447 (2013), pp. 345-360

Rognes et al., 2016 T. Rognes, T. Flouri, B. Nichols, C. Quince, F. Mahé. VSEARCH: a versatile open source tool for metagenomics. PeerJ, 4 (2016), p. e2584 
Russell, 2003 A. Russell. Similarities and differences in the responses of microorganisms to biocides. J. Antimicrob. Chemother., 52 (5) (2003), pp. 750-763

Ruxton, 2006 G.D. Ruxton. The unequal variance t-test is an underused alternative to Student's t-test and the Mann-Whitney U test. Behav. Ecol., 17 (4) (2006), pp. 688-690

Shen et al., 2013 Z. Shen, J. Han, Y. Wang, O. Sahin, Q. Zhang. The contribution of ArsB to arsenic resistance in Campylobacter jejuni. PLoS One, 8 (3) (2013), p. e58894

Suda et al., 2014 K.J. Suda, L.A. Hicks, R.M. Roberts, R.J. Hunkler, T.H. Taylor. Trends and seasonal variation in outpatient antibiotic prescription rates in the United States, 2006 to 2010. Antimicrob. Agents Chemother., 58 (5) (2014), pp. 2763-2766

Timraz et al., 2017 K. Timraz, Y. Xiong, H. Al Qarni, P.-Y. Hong. Removal of bacterial cells, antibiotic resistance genes and integrase genes by on-site hospital wastewater treatment plants: surveillance of treated hospital effluent quality. Environ. Sci.: Water Res. Technol., 3 (2) (2017), pp. 293-303

Tkachenko et al., 2007 O. Tkachenko, J. Shepard, V.M. Aris, A. Joy, A. Bello, I. Londono, J. Marku, P. Soteropoulos, M.A. Peteroy-Kelly. A triclosan-ciprofloxacin cross-resistant mutant strain of Staphylococcus aureus displays an alteration in the expression of several cell membrane structural and functional genes. Res. Microbiol., 158 (8) (2007), pp. 651-658

USFDA, 2016 USFDA. FDA Issues Final Rule on Safety and Effectiveness of Antibacterial Soaps.

FDA Web Site. (2016)

Van Boeckel et al., 2015 T.P. Van Boeckel, C. Brower, M. Gilbert, B.T. Grenfell, S.A. Levin, T.P. Robinson, A. Teillant, R. Laxminarayan. Global trends in antimicrobial use in food animals. Proc. Natl. Acad. Sci. Unit. States Am., 112 (18) (2015), pp. 5649-5654

White et al., 2009 J.R. White, N. Nagarajan, M. Pop. Statistical methods for detecting differentially abundant features in clinical metagenomic samples. PLoS Comput. Biol., 5 (4) (2009), p. e1000352

Wilke et al., 2012 A. Wilke, T. Harrison, J. Wilkening, D. Field, E.M. Glass, N. Kyrpides, K. Mavrommatis, F. Meyer. The M5nr: a novel non-redundant database containing protein sequences and annotations from multiple sources and associated tools. BMC Bioinf., 13 (1) (2012), p. 141

Ying et al., 2007 G.-G. Ying, X.-Y. Yu, R.S. Kookana. Biological degradation of triclocarban and triclosan in a soil under aerobic and anaerobic conditions and comparison with environmental fate modelling. Environ. Pollut., 150 (3) (2007), pp. 300-305

Yu et al., 2010 B.J. Yu, J.A. Kim, J.-G. Pan. Signature gene expression profile of triclosanresistant Escherichia coli. J. Antimicrob. Chemother., 65 (6) (2010), pp. 1171-1177 Zhu et al., 2010 L. Zhu, J. Lin, J. Ma, J.E. Cronan, H. Wang. Triclosan resistance of Pseudomonas aeruginosa PAO1 is due to FabV, a triclosan-resistant enoyl-acyl Carrier protein reductase. Antimicrob. Agents Chemother., 54 (2) (2010), pp. 689-698 
Appendix A. Supplementary data

The following are the supplementary data related to this article:

Supporting Information

\section{Metagenomics reveal triclosan-induced changes in the antibiotic resistome of anaerobic digesters}

Masanori Fujimoto $^{1 \#}$, Daniel E. Carey ${ }^{1 \wedge}$, Patrick J. McNamara ${ }^{1 *}$.

${ }^{1}$ Department of Civil, Construction and Environmental Engineering, Marquette University, Milwaukee, WI

*Corresponding Author e-mail: patrick.mcnamara@mu.edu

Current affiliations

\# Department of Soil and Water Sciences, University of Florida, Gainesville, FL, USA

${ }^{\wedge}$ Brown \& Caldwell, Charlotte, North Carolina, USA

\section{Content}

Figure S1. Rarefaction curve of species count based on functional gene annotation using m5nr database

Figure S2. Phylum-class level stacked bar plot across different TCS concentrations S2

\section{Pages: 2}

Figures: 2 


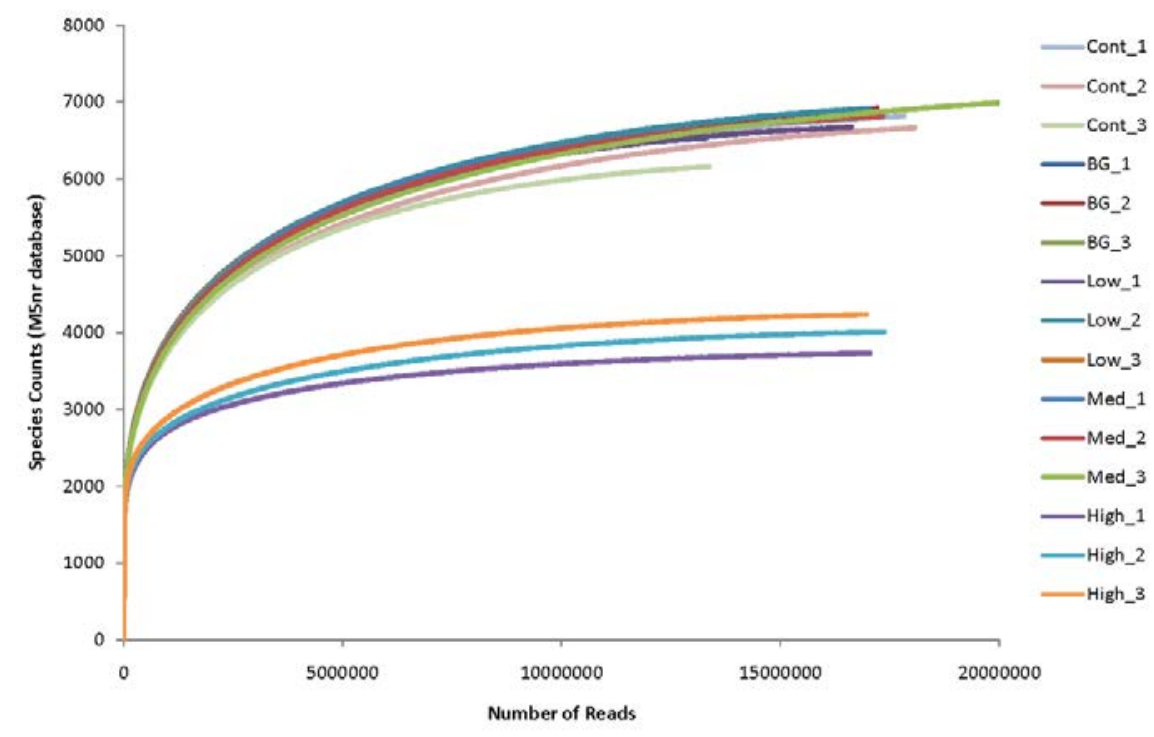

Figure S1. Rarefaction curve of species count based on functional gene annotation using m5nr database

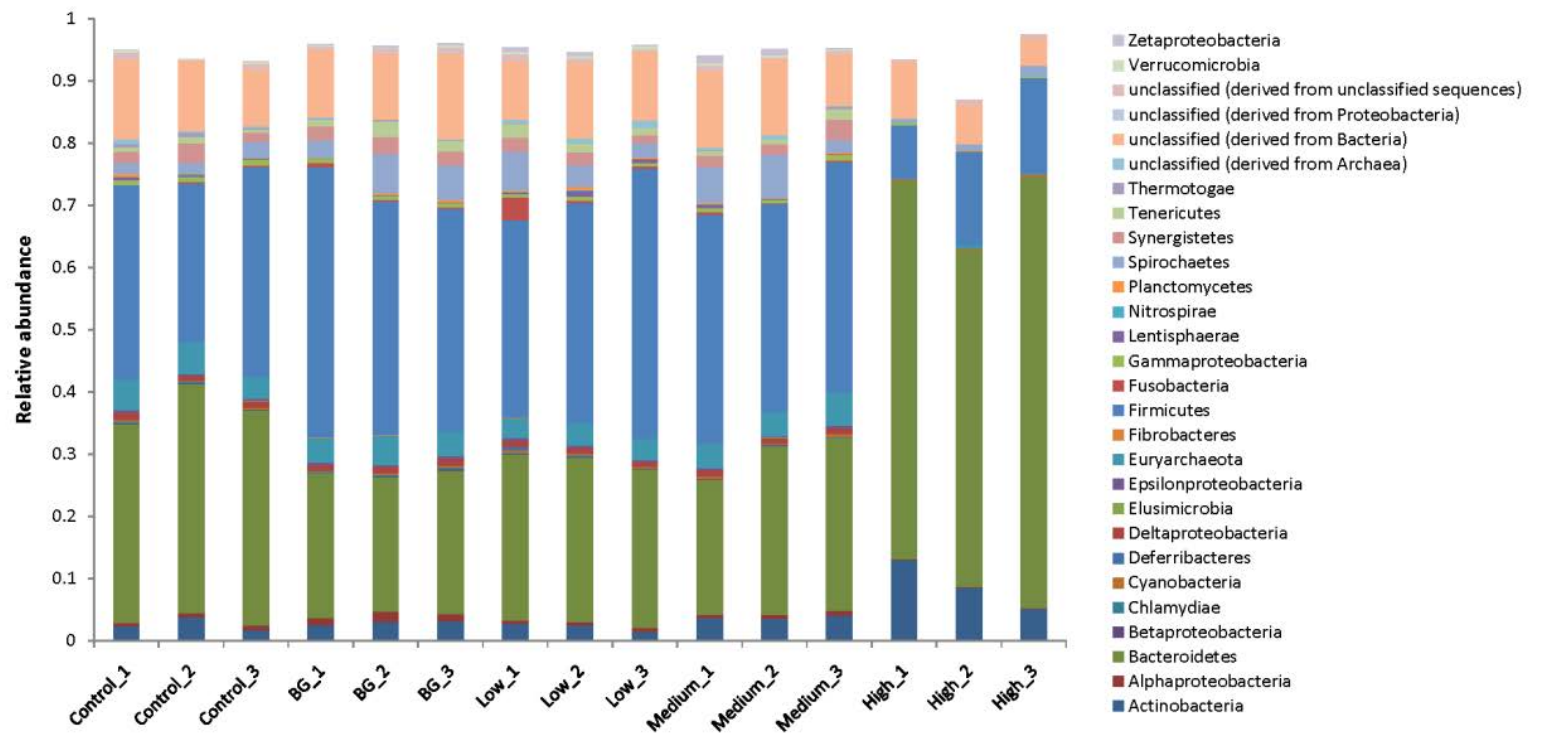

Figure S2. Phylum-class level stacked bar plot across different TCS concentrations

For Figure S3, see separate attachment. 


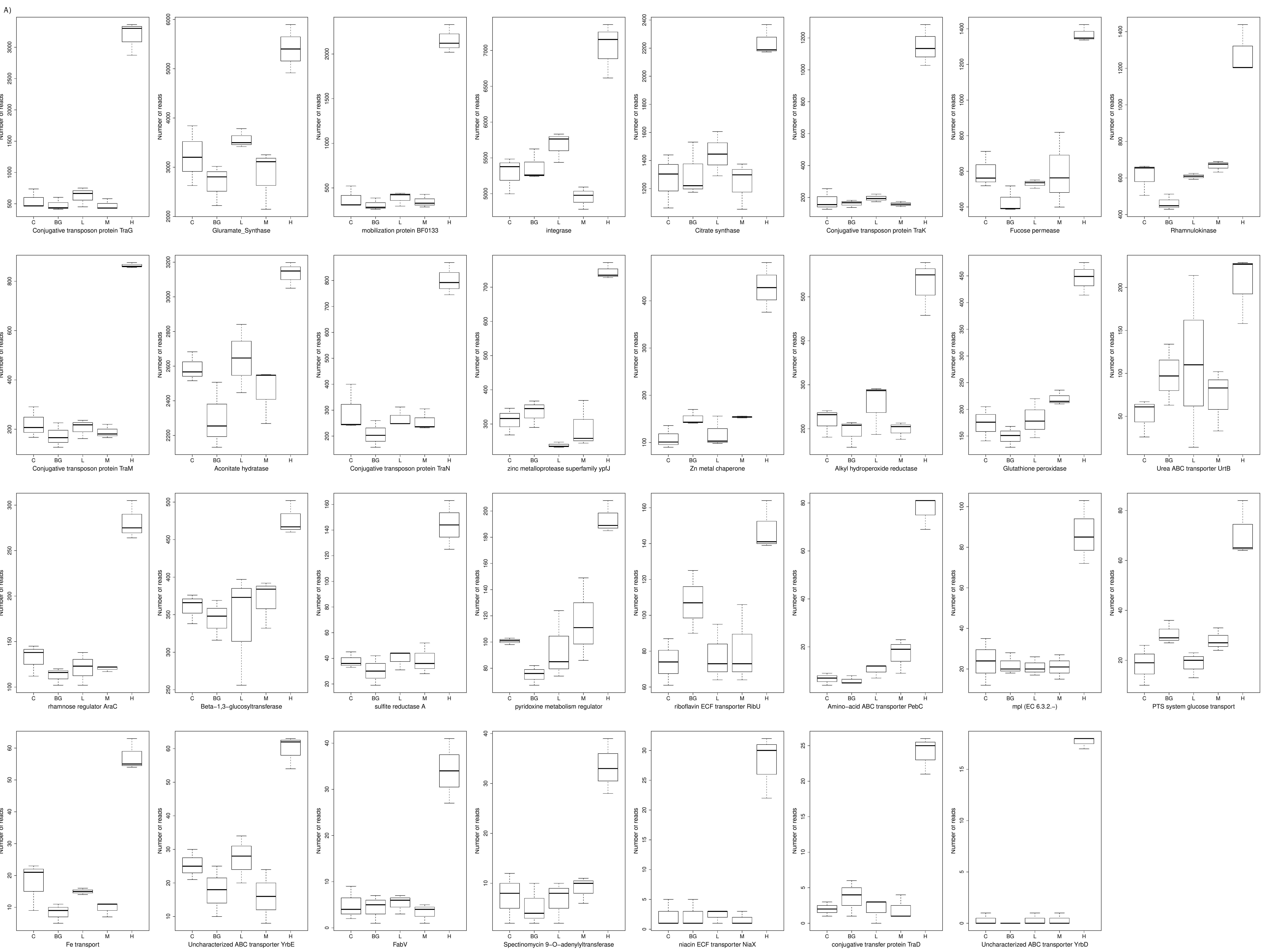




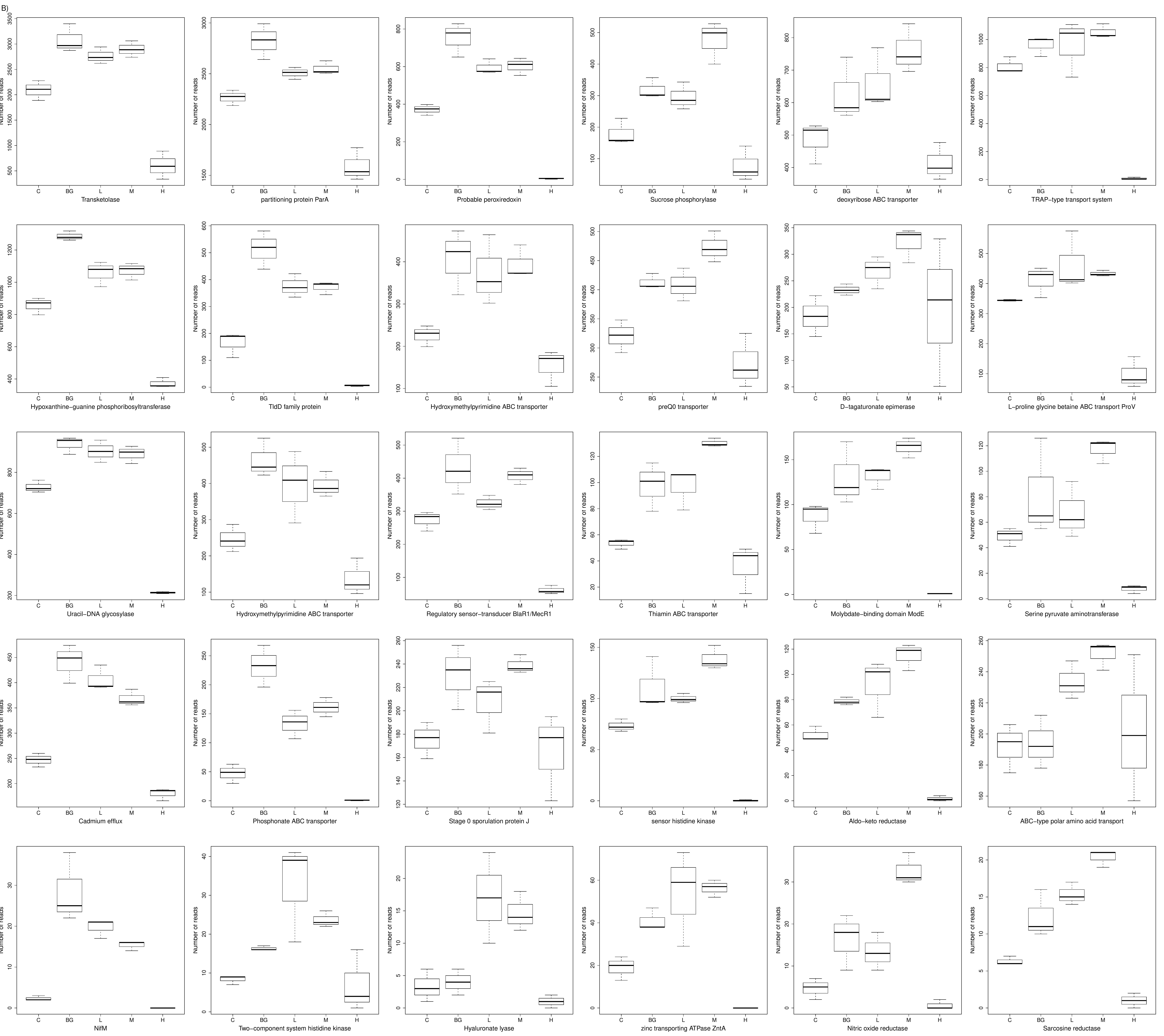


